\title{
La reversión por la administración de las contratas: perspectiva desde el derecho del trabajo
}

\section{Reversion by the administration of the contracts: perspective from the labor law}

\author{
Juan Gorelli Hernández \\ Universidad de Huelva (España) \\ ORCID: http://orcid.org/0000-0003-4452-3068 \\ juan.gorellli@dam.uhu.es
}

\section{NOTA BIOGRÁFICA}

Doctor en Derecho por la Universidad de Sevilla. Catedrático de Derecho del Trabajo y de la Seguridad Social. Consejero Electivo del Consejo Consultivo de Andalucía. Entre sus principales líneas de investigación destacan las dedicadas a la extinción del contrato de trabajo, negociación colectiva, tiempo de trabajo, conciliación de la vida familiar y laboral de las personas trabajadoras y Seguridad Social.

\section{RESUMEN}

El presente trabajo analiza la actual dinámica de los procesos de reversión o remunicipalización de servicios públicos, si bien desde la perspectiva laboral de la cuestión y respecto de la principal de las posibles consecuencias que pueden producirse en este ámbito: la subrogación empresarial, por la que se incorporan a las Administraciones Públicas personal procedente de empresas privadas. Se estudian los principales supuestos que dan lugar a la subrogación como consecuencia de que la reversión pueda ser calificada como sucesión de empresas; y se señalan cuáles son los principales problemas jurídicos que se plantean, especialmente desde el punto de vista del respeto a los principios constitucionales de igualdad, mérito y capacidad; así como la evolución normativa más reciente por la que se pretende limitar los efectos de la incorporación de este personal a las Administraciones Públicas.

\section{PALABRAS CLAVE}

Administración; estabilidad en el empleo; reversión; subrogación.

\begin{abstract}
The present work analyzes the current dynamics of the processes of reversion or remunicipalization of public services, although from the labor perspective of the question and with respect to the main one of the possible consequences that can take place in this field: the business subrogation, by which is incorporated into the Public Administration personnel from private companies. The main assumptions that lead to subrogation are studied as a consequence of the fact that the reversal can be classified as a succession of companies; and they indicate which are the main legal problems that arise, especially from the point of view of the respect to the constitutional principles of equality, merit and capacity; as well as the most recent normative evolution by which it is intended to limit the effects of the incorporation of these personnel to Public Administrations.
\end{abstract}

\section{KEYWORDS}

Administration; stability in employment; reversion; subrogation. 


\section{SUMARIO}

1. INTRODUCCIÓN. 2. LA APLICACIÓN DE LAS REGLAS SOBRE SUCESIÓN DE EMPRESAS A LAS ADMINISTRACIONES PÚBLICAS. 3. REVERSIÓN Y SUBROGACIÓN LEGAL EX ART. 44 ET. 4. TITULARIDAD PÚBLICA DE LOS MEDIOS MATERIALES DE PRODUCCIÓN Y SUBROGACIÓN LEGAL. 5. REVERSIÓN Y SUCESIÓN DE PLANTILLAS. 6. REVERSIÓN Y SUBROGACIÓN CONVENCIONAL O CONTRACTUAL. 7. SUBROGACIÓN Y PRINCIPIOS DE IGUALDAD, MÉRITO Y CAPACIDAD. 8. LIMITACIONES A LA REVERSIÓN: LA DISPOSICIÓN ADICIONAL 26. ${ }^{a}$ DE LA LPGE PARA 2017.

\section{INTRODUCCIÓN}

La reversión supone la decisión de la Administración de recuperar la gestión de aquellos servicios que, siendo de su titularidad, estaban siendo gestionados por una empresa privada (Cruz, 2016, 41).

La reversión es una posibilidad cuyo fundamento reside en la potestad de autoorganización que tienen las Administraciones. Al igual que la Administración puede, en base a dicha potestad, proceder a la externalización de ciertas áreas de su gestión; también pueden tomar la decisión inversa, recuperando para sí la gestión de las mismas. Se trata de llevar a la práctica un mero juicio de oportunidad por parte de la Administración, que quiera revertir la forma de gestión de sus servicios.

Como es lógico, lo más oportuno es la recuperación de la gestión una vez que haya finalizado el negocio jurídico entre la Administración y el sujeto privado que desarrollaba la actividad. En este caso la reversión es la consecuencia lógica de la finalización de dicho negocio; si bien puede perfectamente evitarse la reversión por el procedimiento de volver a la licitación pública del mismo, de manera que se produzca una sucesión de concesiones o conciertos. Puede incluso establecerse de manera expresa la reversión en el propio contrato que se celebren entre las partes, de manera que se acuda a un mecanismo concesional, tras el cual la Administración recupera dicha actividad; si bien este tipo de pactos no es necesario, pues hemos de insistir que la externalización no supone la pérdida por parte de la Administración de la titularidad del servicio público.

También es factible la recuperación de la actividad ante tempus, siendo la situación más evidente aquella en la que se producen incumplimientos esenciales de los pliegos de condiciones por una de las dos partes, de manera que la actividad vuelve a revertir sobre la Administración como consecuencia de la resolución del contrato. En estos casos la parte incumplidora deberá indemnizar a la contraparte.

Cabe advertir que dicha reversión puede realizarse a cualquiera de las modalidades de gestión directa que hemos señalado anteriormente; es decir, que la Administración puede recuperar la gestión para ejercerla directamente sin entidad personalizada, o mediante una entidad con personalidad jurídica propia.

Lo cierto es que la reversión es un escenario perfectamente posible dentro del marco de la gestión pública. De hecho, se está asistiendo, sobre todo especialmente en el ámbito de las Administraciones locales, se habla así de «remunicipalización», respecto del proceso de reversión de servicios que habían sido externalizados (López, 2017, 105. No es, por tanto, extraño que en la actualidad se haya detectado un freno a las prácticas externalizadoras e incluso una marcha atrás en este proceso (Navarro, 2016, 312). Lo realmente paradójico de este cambio de dirección es que se haya justificado con los mismos argumentos que sirvieron para desencadenar el proceso de externalización: la reducción del gasto público, buscando una mayor eficiencia y la mejora de la calidad de los servicios (Navarro, 2016, 312). Ello supone, de un lado, que finalmente el proceso de descentralización no ha supuesto una mayor eficiencia en la gestión pública, sino que se ha producido un incremento del gasto en la gestión de los servicios públicos como consecuencia de la participación de sujetos privados. De otro lado, se ha constatado que los mecanismos de externalización han supuesto un deterioro en la calidad del servicio público, existiendo una directa relación entre la calidad en el servicio y la calidad en el empleo y poniendo de manifiesto que un servicio de alta calidad requiere un empleo de alta calidad (Olarte, 2016, 159 y 161; Rodríguez, 2017, 22; De la Puebla, 2016, 112). Todo este planteamiento ha hecho que se estén produciendo fenómenos de reversión, de manera que la gestión vuelve a manos públicas, lo cual hace que deban plantearse todo un conjunto de consecuencias laborales a las que vamos a prestar atención a continuación.

Siendo posible la reversión en el ámbito de la sanidad pública, hemos de plantearnos la problemática laboral que una decisión de estas características puede suponer; y desde mi punto de vista, tres son las cuestiones fundamentales a tener en cuenta en este caso: en primer lugar, si de producirse una reversión, resulta de aplicación la subrogación contractual, de manera que la Administración deba subrogarse respecto de los trabajadores que desarrollaban la prestación de trabajo propia de la gestión del servicio público. En 
segundo lugar, la problemática que se suscita, si se produce la incorporación de estos trabajadores procedentes de una empresa privada al sector público, por la afectación de los principios de publicidad, igualdad, mérito y capacidad en el acceso a la función pública. Por último, la reciente reacción del legislador contraria a los efectos de una ola de reversiones en el ámbito público, fundamentalmente por las consecuencias laborales que ello puede suponer.

\section{LA APLICACIÓN DE LAS REGLAS SOBRE SUCESIÓN DE EMPRESAS A LAS ADMINISTRACIONES PÚBLICAS}

Uno de los principales problemas que va a plantearse cuando la Administración decide rescatar un servicio que venía siendo prestado por una empresa privada (un supuesto de gestión indirecta de servicio público), en este caso y por lo que a nosotros interesa, es el destino de los trabajadores afectados; es decir, aquellos que venían desarrollando su prestación de servicios para las empresas privadas que habían sido contratadas por la Administración para el desarrollo del servicio. Estos trabajadores no son personal de la Administración, sino trabajadores, con contratos laborales absolutamente ordinarios, de las empresas contratistas. Por lo tanto, la respuesta lógica sería estimar que la Administración nada tiene que ver con los mismos, por lo que éstos seguirán, en el mejor de los casos desarrollando su prestación de servicios para la contratista, salvo que la pérdida de la concesión o concierto suponga una reducción de la actividad que justifique un despido, normalmente objetivo; o bien que los trabajadores con contrato temporal de obra y servicio vean extinguido el contrato al condicionarse este a la vigencia de la relación entre contratista y Administración (vid. las SSTS de 9 de febrero de 2016, RJ/2016/1197; y 16 de junio de 2016, RJ/2016|331).

Sin embargo, laboralmente encontramos una importante regla destinada a favorecer la estabilidad en el empleo de los trabajadores, me refiero a la subrogación empresarial. Nuestro ordenamiento y nuestra jurisprudencia admite la aplicación de la subrogación empresarial cuando se produce una sucesión de contratistas para la Administración Pública, considerando que en estos casos puede ocurrir que estemos ante una sucesión de empresas de las reguladas por el art. 44 ET. En realidad, hay diferentes supuestos o situaciones en las que puede producirse una sucesión de empresas entre un contratista saliente y el entrante, dando lugar a la subrogación empresarial: una subrogación legal si se cumplen los requisitos del art. 44 ET, de manera que se produce una transmisión de equipamiento o bienes que permiten el desarrollo de la actividad productiva, o una sucesión de plantillas en aquellos casos en los que la actividad productiva depende directamente de la actividad de los trabajadores, sin que sea relevante la utilización de un conjunto de bienes productivos. Junto con la subrogación legal, también es posible la subrogación convencional o pactada en convenio colectivo; e incluso la subrogación contractual o establecida en el pliego de condiciones.

Debe tenerse en cuenta que, si bien la sucesión de contratas no es un fenómeno que deba calificarse necesariamente o por su propia naturaleza como transmisión de empresa (que genera la subrogación), no obstante, es posible que, a tenor de las circunstancias, la sucesión de contratistas genere un supuesto de sucesión de empresas y de subrogación. Debemos preguntarnos si este fenómeno es o no trasladable al supuesto en que la Administración, en vez de proceder a una sucesión de contratistas, decide asumir por sí misma el servicio público nuevamente. El momento en el que nos planteamos esta cuestión es tremendamente interesante, pues asistimos a todo un conjunto de manifestaciones jurisprudenciales sobre esta cuestión, que hacen que éste sea un tema de plena actualidad.

El punto de partida es recordar una cuestión esencial: la Directiva 2001/23 resulta de aplicación a la Administración pública: el art. $1.1 \mathrm{c}$ ) de la Directiva señala que «La presente Directiva será aplicable a empresas tanto públicas como privadas que ejerzan una actividad económica, con o sin ánimo de lucro. La reorganización administrativa de las autoridades públicas administrativas y el traspaso de funciones administrativas entre autoridades públicas administrativas no constituirán un traspaso a efectos de la presente Directiva». Por lo tanto, sólo queda fuera de la Directiva y de las reglas de tuteladoras de trabajadores en caso de transmisión de empresas, la reorganización administrativa. Esta aplicación a las Administraciones públicas se ha reiterado por parte de la jurisprudencia; así, la jurisprudencia comunitaria ha afirmado «que el mero hecho de que el cesionario de la actividad sea un organismo de derecho público, en el caso de autos un ayuntamiento, no permite excluir la existencia de una transmisión comprendida en el ámbito de aplicación de la Directiva 2001/23» (STJUE de 20 de enero de 2011, asunto C-463/09 caso CLECE, TJCE|2011/4, con cita de diversa jurisprudencia; de igual manera la STJUE de 26 de noviembre de 2015, asunto C-509/14, caso ADIF, TJCEI2015/283); siendo, como es lógico, aceptado este planteamiento por la jurisprudencia 
nacional: así la STS de 21 de abril de 2015, RJI2015|2177: «(...) el mero hecho de que el cesionario de la actividad sea un organismo de Derecho público, no permite excluir la existencia de una transmisión comprendida en el ámbito de aplicación de dicha Directiva (...), puesto que la circunstancia de que la transmisión se derive de decisiones unilaterales de los poderes públicos y no de un acuerdo de voluntades no excluye la aplicación de la Directiva». En idéntico sentido la STS de 30 de mayo de 2011, RJI2011/5818. Por lo tanto, no cabe duda alguna sobre esta cuestión (Navarro, 2016, 313-314; De la Puebla, 2016, 112; Sala, 2018, 203).

Tal como acabamos de ver, la Administración Pública no es un ámbito excluido de la aplicación de las reglas sobre sucesión de empresas y subrogación empresarial. Consecuentemente, hemos de plantearnos si el fenómeno de la reversión supone o genera una situación que puede ser calificada de sucesión empresarial y en el que, la Administración ha de subrogarse en los trabajadores de la empresa contratista saliente, que gestiona el servicio. En todo caso, ha de advertirse que al existir diferentes vías en las que se admite la subrogación por parte del ordenamiento y de la jurisprudencia, tendremos que analizarlas de manera separada.

\section{REVERSIÓN Y SUBROGACIÓN LEGAL EX ART. 44 ET}

La denominada subrogación legal es aquella que se produce de conformidad a lo dispuesto por el art. $44 \mathrm{ET}$; es decir, cuando hay una verdadera transmisión de empresa (a tenor de los requisitos establecidos por el citado art. $44 \mathrm{ET}$ ), generando los efectos tuteladores para los trabajadores tal como los establece el propio art. $44 \mathrm{ET}$.

Recordemos que a tenor del art. 44 ET se produce una sucesión de empresa «cuando la transmisión afecte a una unidad económica que mantenga su identidad, entendida como un conjunto de medios organizados a fin de llevar a cabo una actividad económica, esencial o accesoria». Podemos decir, por lo tanto, que con carácter general, la reversión de un servicio no implica necesariamente la transmisión y la subrogación (en este sentido la STS de 17 de noviembre de 2014, RJI2014l6467). Para que haya una sucesión de empresas, la empresa saliente ha de transmitir a la entrante (en este caso la Administración reversora) un conjunto de bienes materiales orientados y organizados para la consecución de un fin productivo. Habrá, por lo tanto, sucesión de empresas ex art. 44 ET y subrogación de los trabajadores, que se incorporarán a la Administración, si se produce una reversión en la que la Administración recibe un conjunto de bienes que permiten el desarrollo de la actividad productiva; por el contrario, no existirá sucesión si en la reversión no se produce una transmisión en tales términos (Gómez, 2004, 221). Así lo ha venido admitiendo la jurisprudencia, sin que el hecho de que se trate de una reversión deba recibir un trato diferenciado a los efectos de determinar si hay sucesión o no de empresas.

Partiendo de la jurisprudencia comunitaria, y para supuestos de reversión por parte de Administraciones españolas, se ha afirmado por parte de la STJUE de 29 de julio de 2010, C-151/09 caso UGT-FSP, TJCE\20101241, supuesto en que el Ayuntamiento de La Línea revierte la actividad desarrollada por cuatro contratistas, que «la transmisión debe referirse a una entidad económica organizada de forma estable cuya actividad no se limite a la ejecución de una obra determinada. El concepto de entidad remite así a un conjunto organizado de personas y elementos que permite el ejercicio de una actividad económica que persigue un objetivo propio», añadiendo que para determinar si se cumple los requisitos para la transmisión de una entidad de estas características debe estarse a todo un conjunto de circunstancias de hecho que caracterizan este tipo de operación, debiendo analizarse los mismos en su conjunto y no de manera aislada, para determinar si estamos o no en una sucesión que determina la subrogación empresarial:

«(...) han de tomarse consideración todas las circunstancias de hecho que caracterizan a la operación de que se trata, entre las cuales figuran, en particular, el tipo de empresa o de centro de actividad de que se trate, el hecho de que se hayan transmitido o no elementos materiales como los edificios y bienes muebles, el valor de los elementos inmateriales en el momento de la transmisión, el hecho de que el nuevo empresario se haga cargo o no de la mayoría de los trabajadores, el que se haya transmitido o no la clientela, así como el grado de analogía de las actividades ejercidas antes y después de la transmisión y la duración de una eventual suspensión de dichas actividades. Sin embargo, estos elementos son únicamente aspectos parciales de la evaluación de conjunto que debe hacerse y no pueden, por tanto, apreciarse aisladamente». 
En la STJUE de 20 de enero de 2011, C-463/09 caso CLECE, TJCE 201114, en el que el Ayuntamiento de Cobisa procedió a la extinción del contrato del servicio de limpieza de las dependencias del propio Ayuntamiento y procedió a realizar dicha actividad contratando para ello a nuevo personal, al analizarse la cuestión, se afirmaba por el TJUE que:

«(...) no puede excluirse de entrada que la Directiva 2001/23 se aplique en circunstancias como las del asunto principal, en las que un ayuntamiento decide unilateralmente poner fin al contrato que lo vinculaba a una empresa privada y hacerse cargo directamente de las actividades de limpieza que había encargado a ésta (...). Sin embargo, conforme al artículo 1, apartado 1, letra b), de la Directiva 2001/23, para que ésta resulte aplicable, la transmisión debe tener por objeto una entidad económica que mantenga su identidad tras el cambio de titular».

Además, esta Sentencia reitera lo afirmado por la STJUE UGT-FSP en relación a los criterios y circunstancias a tener en cuenta que deben analizarse de manera conjunta a la que hemos aludido en el párrafo anterior.

Al igual que en las dos sentencias anteriores, la STJUE de 26 de noviembre de 2015, C-509/14 caso ADIF, TJCE\2015\283, en el que ADIF externalizó la actividad de manipulación de unidades de transporte intermodal, desarrollándolo una empresa privada, que recibió la infraestructura y el equipamiento necesarios propiedad de ADIF, si bien posteriormente se procedió al rescate de la actividad sin hacerse cargo de las trabajadoras, pues se iba a desarrollar por su propio personal. En este caso se realizan similares afirmaciones a las anteriores, tanto en la exigencia de que se transmita una entidad económica, entendida como un conjunto de medios organizados a fin de llevar a cabo una actividad económica; como reiterando el conjunto de criterios a tener en cuenta en una valoración conjunta.

Esta doctrina se ha trasladado a la jurisprudencia laboral española, así, recientemente la STS de 19 de septiembre de 2017; RJI2017\4447, al dilucidar un supuesto en el que el Ministerio de Defensa reasumía el servicio de cocina y restauración desarrollado por una empresa contratista privada, afirmaba que:

«El hecho de que una Administración Pública decida hacerse cargo de un servicio, previamente descentralizado, para prestarlo de forma directa con su propia plantilla y con sus propios materiales no implica, necesariamente, que estemos en presencia de una sucesión de empresa comprendida dentro del ámbito de aplicación de la Directiva 2001/23/CEE y, por ende, del artículo 44 ET. Así lo ha venido señalando, reiteradamente nuestra jurisprudencia, entre otras en la lejana STS de 6 de febrero de 1997 en la que dijimos que "la doctrina de esta Sala es constante al afirmar con carácter general que la extinción de la contrata y la asunción con trabajadores propios de la actividad antes descentralizada no constituye, por sí misma, un supuesto de subrogación empresarial", y en la más reciente STS de 26 de julio de 2012 conforme a la cual no se produce sucesión empresarial cuando "no consta transmisión alguna de elementos patrimoniales o estructura organizativa ni tampoco la asunción por el Ayuntamiento codemandado de una parte sustancial de la plantilla". Doctrina reiterada en STS de 16 de junio de 2016».

Por lo tanto, la reversión, al igual que las sucesiones de contratistas, por sí mismas no constituye una sucesión de empresas, salvo que se produzca la transmisión de los elementos patrimoniales o estructuras organizativas que permiten el desarrollo de la actividad productiva. De hecho esta Sentencia (y en idéntico sentido a la STS de 19 de septiembre de 2017, RJI2017\4527) se remite a la doctrina del TJUE y concretamente a la Sentencia de 20 de enero de 2011, asunto CLECE ya señalada, para entender que la subrogación se produce cuando la transmisión tiene por objeto una entidad económica que mantiene su identidad tras el cambio, concluyendo que:

«Hemos afirmado, también, que el hecho de una administración recupere la prestación del servicio, anteriormente externalizado, bien con los mismos trabajadores que tenía la empresa que prestaba el servicio, bien con las mismas instalaciones, maquinaria, infraestructura que las que utilizaba la empresa contratista, o bien con ambos elementos determina que, normalmente, estemos ante un supuesto de transmisión de empresa que está situado en el ámbito de aplicación del artículo 44 ET. Así en la STS de 30 de mayo de 2011 dijimos que la reversión de un servicio público desde una empresa concesionaria a un Ayuntamiento, que acuerda su gestión a través de empresa municipal, no excluye la aplicación del artículo $44 \mathrm{ET}$, si va acompañada de transmisión de medios materiales». 
De esta manera podemos encontrar todo un conjunto de sentencias del TS en las que se estima la inexistencia de sucesión empresarial, justamente por el hecho de que en la reversión de la actividad desarrollada por las empresas contratistas, no se produce una transmisión de elementos patrimoniales que permitan el desarrollo de la actividad productiva, pasando la Administración a prestar el servicio con su propio personal y con sus propios medios instrumentales. Así, la STS de 26 de septiembre de 2017, RJI2017\4273, que tras recordar la doctrina afirmada por las dos SSTS de 19 de septiembre de 2017 que acabamos de mencionar supra, así como la doctrina de la STJUE de 20 de enero de 2011, asunto CLECE, señala que:

«(...) aquí nos encontramos ante la reversión de un servicio de información, atención al cliente y servicios auxiliares en la estación de Atocha de Madrid, que descansa fundamentalmente en la mano de obra, y que pasa a prestarse por la entidad pública empresarial con su propio personal, habiendo señalado la sentencia recurrida que no existen elementos materiales o patrimoniales al objeto de configurar una infraestructura u organización empresarial por lo que claramente estamos en presencia de una actividad que descansa fundamentalmente en la mano de obra. La reversión de la contrata se ha llevado a cabo sin transmisión de elementos patrimoniales y sin que la principal se hiciera cargo de ningún trabajador de la contratista dado que ha asumido la contrata con sus propios trabajadores (...) En consecuencia, no constan en el supuesto de autos datos que posibiliten la aplicación de la Directiva ni del art. 44 ET.».

De la misma manera, las SSTS de 9 de febrero de 2016, RJI2016/1197 y 16 de junio de 2016, RJI201613331, dictadas en un supuesto de reversión del servicio de mantenimiento de centros de enseñanza pública de la Comunidad Autónoma de Canarias, Administración que pasó a desarrollar tales actividades con su propio personal, volviendo posteriormente a licitar la actividad siete meses después aportando la dicha nueva contratista personal contratado por ella, así como los medios materiales y herramientas para el desarrollo de la actividad, estimo la inexistencia de subrogación, tanto respecto de la Administración como para la nueva contratista que se ocupó de la actividad meses después (en este caso, debe tenerse en cuenta que los trabajadores vieron extinguidos sus contratos). La Sentencia partía de entender que la sucesión de contratistas no es un supuesto de subrogación legal, salvo que se produzca la transmisión de los elementos patrimoniales que configuran la infraestructura necesaria u organización empresarial básica para la explotación de la actividad; pudiendo, no obstante, producirse por imposición de normas convencionales o pliego de condiciones (lo cual en dicho caso no sucedía en ninguna de tales posibilidades). La misma doctrina se aplica a las Administraciones cuando estas rescatan un servicio, por lo que se rechazaba que hubiese un supuesto de sucesión empresarial y subrogación de los trabajadores.

También podemos señalar a la STS de 21 de abril de 2015, RJ\2015\2177, que se dictó ante un supuesto en el que la Intervención General del Estado recuperaba el servicio de cafetería, sin que se produjese la transmisión de los elementos patrimoniales, e incluso en el que no se reanudaron los servicios objeto de la contrata. En esta sentencia, partiendo de la doctrina jurisprudencial propia de sucesiones entre contratistas privados, a tenor de la que la contrata no es un supuesto de unidad productiva autónoma, salvo que se transmita al contratista entrante por el saliente la infraestructura necesaria u organización empresarial básica o salvo que se trate de un supuesto de sucesión de plantillas, se negó que la reversión en este caso fuese sucesión y se generase la subrogación empresarial. El supuesto de hecho es muy similar al de la STS de 19 de mayo de 2015, RJ\2015\2886, relativa a una recuperación del servicio de restauración del Palacio de Congresos de Madrid. De igual manera la STS de 9 de diciembre de 2017, RJI2017\206, relativa a la reversión a la Administración del servicio de apoyo de monitores de comedor de un centro de enseñanza.

En la dirección contraria, es decir, aceptando la existencia de sucesión de empresa y subrogación de los trabajadores, que pasarían a trabajar para la Administración, podemos encontrar supuestos en los que sí se produjo la transmisión de medios materiales para el desarrollo de la actividad productiva en una situación de reversión. Así, se ha estimado la existencia de sucesión en el caso de la STS de 30 de mayo de 2011,RJ/2011/5818, en el que el Ayuntamiento de Sevilla concertó la prestación de servicios de grúa municipal con una determinada empresa, resolviéndose el contrato por incumplimiento e incautándose de los medios materiales para el desarrollo de la actividad, contratando a una nueva concesionaria, que se subrogó en la actividad y a la que el Ayuntamiento hace entrega de los mencionados medios materiales, decidiéndose años después la reversión para prestar los servicios directamente el Ayuntamiento. En este caso la sentencia estimó la existencia de la sucesión, aceptando la responsabilidad solidaria de la Administración por salarios impagados a los trabajadores al entender que: 
«se trata de la transmisión de "un conjunto de medios organizados, a fin de llevar a cabo una actividad económica" [art. 1 b) de la Directiva 2001/23 ], la "unidad patrimonial susceptible de ser inmediatamente explotada" de que habla -desde siempre- nuestra doctrina jurisprudencial (valgan de ejemplo las SSTS 23/09/97; Sala General 15/04/99; 17/05/00; y 25/02/02). Sin que pueda argumentarse -en contra de esta conclusión- que los elementos patrimoniales ya eran propiedad municipal y que ello nos sitúa frente a una simple reversión de medios [no determinante de sucesión empresarial], que no transmisión de los mismos, puesto que el argumento únicamente sería válido si se tratase de una propiedad municipal originaria, y no es viable cuando -como en autos- los citados componentes materiales habían sido previamente "incautados" a "Servicleops, S. L." y su utilización pasó sin solución de continuidad a las nuevas concesionarias [primero "Setex Aparki S. A.", posteriormente -aunque sin ejercicio efectivo de la gestión transmitida a la entidad municipal- a "Tussam" y en último término a "Aussa"]».

Idéntica solución se da por la STS de 26 de enero de 2012, RJI2012/2462 (de igual manera y sobre supuesto idéntico respecto del mismo Ayuntamiento y servicio revertido, la STS de 11 de junio de 2012, RJI201218334), ante otro problema de reclamación de salarios, de trabajadores que desarrollaban las funciones de cuidadores en un Centro Residencial titularidad del Ayuntamiento de Membrio, siendo contratados por una empresa a la que se adjudicó la gestión del mencionado Centro, que revirtió al Ayuntamiento, asumiendo éste la gestión y explotación temporalmente (para lo que contrató también temporalmente a los trabajadores) hasta una nueva adjudicación; habiendo dejado de abonar cuantías salariales la primera contratista. Esta última Sentencia aplicó la doctrina ya afirmada por la STS de 30 de mayo de 2011, por lo que se declaró la responsabilidad solidaria del Ayuntamiento.

La conclusión a la que puede llegarse es que, si bien la reversión no es en sí misma un supuesto o situación de sucesión de empresas, sin embargo, en aquellos casos en los que se transmite la organización productiva, estaremos dentro del ámbito del art. $44 \mathrm{ET}$ y, consecuentemente, será de aplicación la subrogación empresarial prevista como mecanismo de tutela para los trabajadores prevista por el citado precepto; siendo ésta también la posición que puede encontrarse entre la doctrina laboral López, 2017, 122 y 123; Madrigal y Martínez, 2015, 38; Monereo, 2016, 290; Navarro, 2016, 313; Rodríguez, 2017, 23 y 24; De la Puebla, 2017, 113 y 114; Sala, 2018, 203).

\section{TITULARIDAD PÚBLICA DE LOS MEDIOS MATERIALES DE PRODUCCIÓN Y SUBROGACIÓN LEGAL}

Acabamos de hacer referencia a un supuesto (la STS de 30 de mayo de 2011) en el que se estima la sucesión y la subrogación de trabajadores cuando los bienes que se utilizan para el desarrollo de la actividad son propiedad de la Administración, pero como consecuencia de una apropiación por incumplimiento de la contratista, siendo utilizados tales medios instrumentales por la posterior contratista y posteriormente revertidos sobre la Administración. En este caso el TS estima que hay transmisión de empresa y no una mera reversión de medios. La misma Sentencia parece entender que la respuesta no sería la misma en el caso en que los bienes fueran originariamente propiedad de la Administración; sin embargo, este es un mero obiter dicta, una opinión meramente tangencial, por lo que no ha de tenerse como doctrina asentada. Se está así planteando que no habría transmisión de elementos patrimoniales productivos cuando éstos ya eran, originariamente, de la propia Administración, de manera que éstos, simplemente volverían a sus manos sin que hubiese transmisión alguna, pues nunca fue transmitida su propiedad.

Sin embargo Sentencias posteriores han ido por una dirección totalmente diferente. Me refiero al reciente conjunto jurisprudencial originado con la reversión del servicio de cocina y restauración del Ministerio de Defensa, que en este punto se inspira en la ya mencionada STJUE de 26 de noviembre de 2015, caso ADIF, TJCE\2015|283. Recordemos que esta última sentencia resolvía una situación en la que ADIF externalizó la actividad de manipulación de unidades de transporte intermodal, poniendo a disposición de la contratista las infraestructuras y equipamientos necesarios, propiedad de ADIF, para el desarrollo de tal actividad. Al analizar el caso, el TJUE estimó que:

«(...) de una jurisprudencia reiterada del Tribunal de Justicia se desprende que el ámbito de aplicación de esa Directiva abarca todos los supuestos de cambio, en el marco de relaciones contractuales, de la persona física o jurídica responsable de la explotación de la empresa, 
que por este motivo asume las obligaciones del empresario frente a los empleados de la empresa, sin que importe si se ha transmitido la propiedad de los elementos materiales (véanse las sentencias Abler y otros, C-340/01, EU:C:2003:629, apartado 41, y CLECE, C-463/09, EU:C:2011:24, apartado 30) (...) en lo que respecta a la circunstancia de que los elementos materiales indispensables para el desarrollo de la actividad de que se trata en el litigio principal hayan pertenecido siempre a ADIF, procede recordar que, con arreglo a la jurisprudencia citada en el apartado 28 de la presente sentencia, la cuestión de si se ha transmitido la propiedad de los elementos materiales carece de pertinencia a efectos de aplicar la Directiva 2001/23 (...) A este respecto, el Tribunal de Justicia ha declarado que la circunstancia de que los elementos materiales asumidos por el nuevo empresario no pertenecieran a su antecesor, sino que simplemente fueran puestos a su disposición por la entidad contratante, no puede excluir la existencia de una transmisión de empresa en el sentido de esa Directiva (véase, en este sentido, la sentencia Abler y otros, C-340/01, EU:C:2003:629, apartado 42)».

Teniendo en cuenta esta doctrina jurisprudencial, así como algún antecedente procedente de la sucesión de empresas en el sector privado (tal como ocurre con la STS de 28 de abril de 2009, RJI200912997 o la STS de 7 de febrero de 2012, RJ201214970), al resolver el problema de la reversión del Ministerio de Defensa, el TS en sus sentencias de 19 de septiembre de 2017, RJI2017\4447; RJI2017\4527; RJI2017\4481 y RJI2017\4477 (si bien ha de señalarse que todas estas SSTS cuentan con un voto particular contrario a la solución dada al problema en cuestión), no duda en estimar la existencia de sucesión de empresas y aplicar la subrogación empresarial, aceptando que

«ha existido en la operación de reversión del servicio contratado la entrega de los elementos patrimoniales que resultan inevitables para la continuidad de la actividad, lo que revela la transmisión de un conjunto de medios que conforman una determinada actividad económica que mantiene su identidad tras la reasunción del servicio por parte del Ministerio de Defensa. No hay duda, por tanto, de la existencia de un conjunto de medios organizados, a fin de llevar a cabo una actividad económica, ya fuere esencial o accesoria. Conjunción de elementos que determina que estemos en el ámbito de aplicación de la Directiva 2001/23 y del artículo 44 ET. Sin que, por otra parte, resulte de aplicación el artículo 301.4 TRLCSP que se refiere a supuestos distintos -que se caracterizan, precisamente, por la ausencia de una transmisión empresarialde los aquí contemplados en los que, como se avanzó, existe una sucesión de empresa en los términos que establece tanto la Directiva como el artículo 44 ET».

Por lo tanto, cabe afirmar que realmente no existen diferencias sustanciales entre un supuesto de sucesión de contratistas cuando la principal es una empresa privada, o cuando se trata de una Administración que revierte un servicio gestionado anteriormente por una contratista: en ambos casos se podrá estar ante una subrogación legal si es que se cumplen las exigencias del art. 44 ET.

\section{REVERSIÓN Y SUCESIÓN DE PLANTILLAS}

¿Qué ocurre cuando el proceso productivo de la empresa contratada no requiere de especiales medios de producción? Si se produce una sucesión de contratas, al no existir un conjunto de bienes materiales organizados para el desarrollo de una actividad productiva, no habría sucesión de empresa, ni subrogación empresarial: de aplicar la doctrina jurisprudencial tradicional, al no haber una transmisión de elementos materiales, no habría sucesión y no podría aplicarse la subrogación de los trabajadores.

Lo anterior es tremendamente importante, pues hay un amplio conjunto de actividades de prestación de servicios, en los que apenas existe ese conjunto de medios organizados con un objetivo productivo, tal como ocurre con la actividad de limpieza o de seguridad. Sin embargo, en estos procesos productivos, se ha considerado que al ser esencial la mano de obra, habría sucesión si la empresa entrante se hace cargo de todos o la mayoría de los trabajadores, dado que la actividad descansa fundamentalmente en la mano de obra(Rodríguez, 2017, 24; De la Puebla, 2016, 116; Treviño, 2017, 147).

De esta manera, se admitido que en aquellos casos en los que no se requiere un conjunto de medios materiales para el desarrollo de la actividad productiva, sino que la misma se desarrolla gracias simplemente a la actividad de los propios trabajadores (pensemos, por ejemplo, en la actividad de vigilancia o seguridad de los bienes) y sin tales medios de producción, es posible que estemos ante una transmisión de empresa 
de las reguladas por el art. 44 ET (Trillo, 2017, 43). Es decir, habría subrogación empresarial, pese a no producirse una transmisión de un conjunto de medios de producción, cuando el factor esencial para el proceso productivo es la mano de obra (López, 2017, 110; Rodríguez-Piñero, 2016, 142). En este sentido la STS de 10 de julio de 2014, RJI2014/4774:

«(...) la subrogación empresarial que el citado precepto estatutario impone si se produce cuando se transmite una organización empresarial en aquellos supuestos denominados "sucesión de plantillas", en los que la actividad descansa, esencialmente, en el factor humano, en la organización y dirección de la actividad del personal cualificado que se emplea en la ejecución del servicio contratado, en la ejecución de la contrata».

En similar sentido la STS de 9 de julio de 2014, RJ201414637.

El primer paso lo dio la jurisprudencia comunitaria, que partiendo de la existencia de diferentes circunstancias a tener en cuenta, tanto la transmisión de elementos materiales, como inmateriales (clientela, know how, la analogía de las actividades realizadas antes y después de la transmisión, la asunción de la mayoría de los trabajadores, etc.), señala que en los casos en que la actividad se basa en la mano de obra, la asunción de la misma determinaría una sucesión de empresas. Así, la STJUE de 10 de diciembre de 1998, C-173/96 y C-247/96, asunto Sánchez Hidalgo y otros, TJCE\1998|309, que al resolver el supuesto de un Ayuntamiento que adjudica la concesión del servicio de ayuda a domicilio a una determinada empresa y que tras finalizar la concesión se lo adjudicó a una tercera que contrató a todos los trabajadores de la anterior, señaló que

«Dicha entidad, si bien debe ser suficientemente estructurada y autónoma, no entraña necesariamente elementos significativos de activo material o inmaterial. En efecto, en determinados sectores económicos, como los de limpieza y vigilancia, estos elementos se reducen a menudo a su mínima expresión y la actividad descansa fundamentalmente en la mano de obra. Así pues, un conjunto organizado de trabajadores que se hallan específicamente destinados de forma duradera a una actividad común puede constituir una entidad económica cuando no existen otros factores de producción».

Si nos centramos en aquellas manifestaciones jurisprudenciales generadas por situaciones de reversiones o recuperaciones de servicios por las Administraciones, debemos acudir a la ya mencionada STJUE de 29 de julio de 2010, C-151/09, asunto UGT-FSP, TJCEl20101241, que al analizar las diferentes situaciones de sucesión de empresas, estimó que

«Además, el Tribunal de Justicia ha señalado que una entidad económica puede funcionar, en determinados sectores, sin elementos significativos de activo material o inmaterial, de modo que el mantenimiento de la identidad de dicha entidad independientemente de la operación de que es objeto no puede, por definición, depender de la cesión de tales elementos (véanse las sentencias Süzen, antes citada, apartado 18; de 10 de diciembre de 1998, Hernández Vidal y otros, C-127/96, C-229/96 y C-74/97, Rec. p. I-8179, apartado 31, e Hidalgo y otros, C-173/96 y C-247/96, Rec. p. I-8237, apartado 31) (...) Así, el Tribunal de Justicia ha declarado que en la medida en que, en determinados sectores en los que la actividad descansa fundamentalmente en la mano de obra, un conjunto de trabajadores que ejerce de forma duradera una actividad común puede constituir una entidad económica, ha de admitirse que dicha entidad puede mantener su identidad aun después de su transmisión cuando el nuevo empresario no se limita a continuar con la actividad de que se trata, sino que además se hace cargo de una parte esencial, en términos de número y de competencias, del personal que su antecesor destinaba especialmente a dicha tarea. En este supuesto, el nuevo empresario adquiere en efecto el conjunto organizado de elementos que le permitirá continuar las actividades o algunas actividades de la empresa cedente de forma estable (...). Más concretamente, el Tribunal de Justicia ha considerado, en relación con una empresa de limpieza, que un conjunto organizado de trabajadores que se hallan específicamente destinados de forma duradera a una actividad común puede constituir una entidad económica cuando no existen otros factores de producción (sentencia Hernández Vidal y otros, antes citada, apartado 27)».

Esta doctrina fue fielmente seguida por la STJUE de 20 de enero de 2011, C-463/09 asunto CLECE, TJCE\2011\4. 
En definitiva, que siendo esencial la mano de obra y no existiendo un conjunto material de instrumentos objeto de transmisión, habrá sucesión de empresas si la entrante se hace cargo de una parte esencial de la plantilla de la empresa saliente; siendo esencial, esto debe dejarse claro, que la nueva empresa decida asumir al personal, o a la mayor parte del mismo, de la empresa saliente; pues de lo contrario, no habrá sucesión de empresas (López, 2017, 125; Treviño, 2017, 147).

En todo caso, la doctrina del TJUE se ha trasladado a la jurisprudencia nacional en materia de reversión, como no podía ser de otro modo. Así la STS de 7 de diciembre de 2011, RJ/2012\106, que resuelve sobre la contrata de servicios auxiliares en un aeropuerto, habiendo asumido la nueva concesionaria una parte sustancial de la plantilla de la anterior, estimó, a la luz de la jurisprudencia comunitaria, que

«De la doctrina contenida en las sentencias anteriormente consignadas se desprende que en aquellos sectores en los que la actividad descansa fundamentalmente en la mano de obra, un conjunto de trabajadores que ejerce de forma duradera una actividad común puede constituir una entidad económica, que puede mantener su identidad, cuando se produce una transmisión, y el nuevo empresario no sólo continua con la actividad de que se trata, sino que también se hace cargo de una parte esencial del personal del anterior empresario. Por contra, si la actividad de que se trata no descansa fundamentalmente en la mano de obra, sino que exige material e instalaciones importantes, aunque se produzca la continuidad de la actividad por un nuevo empresario y éste asuma un número importante de trabajadores del anterior, no se considera que hay sucesión de empresa si no se transmiten los elementos materiales necesarios para el ejercicio de la actividad (...) nos encontramos ante un supuesto de los llamados de "sucesión de plantillas", sin que el hecho de que la recurrente haya aportado maquinaria propia y elementos materiales desvirtúe lo dicho, porque no se ha probado la importancia de estas aportaciones materiales, mientras que si consta el valor del factor humano, al haberse dado ocupación al 80 por 100 de la anterior plantilla, a la par que los trabajos de jardinería, mudanzas, peonaje, control de acceso y de circulación, así como los de facturación no requieren por lo general una gran inversión en muebles y máquinas, sino, principalmente, en capital humano».

A mi juicio, el principal problema que aporta este planteamiento es que se requiere para estimar la existencia de sucesión de empresas que la empresa entrante asuma, por su propia decisión (voluntariamente) a la mayoría del personal; es decir, que la «sucesión de plantillas» sólo actúa cuando la empresa entrante decide asumir a la plantilla o una parte sustancial de la misma. Por lo tanto, en estos supuestos, si se asume el personal estamos ante una transmisión de empresa, pero si no se asume al personal (por el simple hecho de que la empresa lo rechace), no estaremos ante una sucesión de empresas. Así la STJU de 20 de enero de 2011, C-463/09, asunto CLECE, TJCEI2011/4: «En particular, la identidad de una entidad económica como la controvertida en el asunto principal, que descansa esencialmente en la mano de obra, no puede mantenerse si el supuesto cesionario no se hace cargo de la mayor parte de su plantilla». De igual manera la STJUE de 26 de noviembre de 2015, C-509/14, asunto ADIF, TJCEl2015/283: «Es cierto que el Tribunal de Justicia ha declarado a este respecto que, en un sector en el que la actividad se basa esencialmente en la mano de obra, la identidad de una entidad económica no puede mantenerse si el supuesto cesionario no se hace cargo de la mayor parte de su plantilla» (vid. un amplio análisis de esta Sentencia en Monereo, 2016, 294 y ss.).

No resulta, por tanto, obligatoria la subrogación, dependiendo ésta de una decisión de la empresa entrante o de la Administración, que unilateralmente y sólo en base a sus intereses determinará si existe o no sucesión (Monereo, 2016, 291; Rodríguez, 2017, 26; Treviño, 2017, 148 y ss.) La cuestión es si debería darse un paso más para estimar que en los casos de actividades donde la mano de obra es esencial y no requieren de un conjunto material relevante, la sucesión de contratas es sucesión de empresas pues hay transmisión de una unidad productiva, dado que lo esencial es la continuidad de la actividad productiva, ante un cambio de sujeto que organiza la actividad productiva ejerciendo las facultades directivas empresariales; todo ello con independencia de la voluntad de la empresa entrante de asumir o no al personal de la empresa saliente. Lo contrario supone dejar a la voluntad de la empresa entrante que la sucesión de contratas, o en el caso que a nosotros interesa, la Administración en caso de reversión, decida si hay o no subrogación; si le interesa o no aplicar el régimen legal de la sucesión de empresas contenido en el art. 44 ET. Dicho régimen legal debe ser obligatorio para la empresa o la Administración, cuando se cumplan los requisitos de dicho precepto, interpretados de la manera flexible que hemos señalado en caso de actividades en que el proceso productivo descansa fundamentalmente en la mano de obra. En todo caso, ha de admitirse que esta interpretación nos conduce, justamente, a dar la vuelta totalmente a la doctrina predominante en los 
últimos decenios que distinguía entre transmisión de empresa y transmisión de actividad (sobre la cuestión, vid. Gorelli, 2007, 288 y ss.).

Tal como acabamos de señalar, se estima la existencia de sucesión empresarial solo si hay asunción de los trabajadores, por lo que en idénticos casos al anterior, pero con la diferencia de que la Administración decide la reversión y desarrollar la actividad con su propia plantilla, va a estimarse que no existe dicha sucesión, por lo que no podrá aplicarse la subrogación a los trabajadores, que quedarán abocados a la extinción de sus contratos por la empresa saliente ${ }^{1}$. Podemos ver, así la STS de 26 de septiembre de 2017 , RJI2017\4273, supuesto en el que ADIF reasumió el servicio de información, atención al cliente y servicios auxiliares en la estación de Atocha, actividad que se realiza fundamentalmente gracias a la mano de obra y sin necesidad de un conjunto de elementos patrimoniales. La empresa decidió desarrollar dicha actividad con su propio personal, sin asumir mano de obra alguna procedente de la contratista saliente. En este caso, se consideró que no había sucesión de empresas, pues tras analizar la doctrina que ha establecido la jurisprudencia comunitaria sobre la sucesión de plantillas, considera que:

«La proyección de tal doctrina en el actual supuesto requiere recordar que aquí nos encontramos ante la reversión de un servicio de información, atención al cliente y servicios auxiliares en la estación de Atocha de Madrid, que descansa fundamentalmente en la mano de obra, y que pasa a prestarse por la entidad pública empresarial con su propio personal, habiendo señalado la sentencia recurrida que no existen elementos materiales o patrimoniales al objeto de configurar una infraestructura u organización empresarial por lo que claramente estamos en presencia de una actividad que descansa fundamentalmente en la mano de obra. La reversión de la contrata se ha llevado a cabo su transmisión de elementos patrimoniales y sin que la principal se hiciera cargo de ningún trabajador de la contratista dado que ha asumido la contrata con sus propios trabajadores».

En idéntica dirección la STS de 9 de diciembre de 2016, RJ/2017/206, que resuelve un caso prácticamente idéntico en el que la Comunidad de Castilla-La Mancha gestiona un IES en el que presta servicio de monitores en un comedor escolar una contratista, finalizando la contrata y asumiendo la Administración el desarrollo de tales funciones directamente, sin asumir personal alguno de la contratista saliente. La Sentencia desestimo la existencia de sucesión empresarial, afirmando

«que en absoluto estamos en presencia de una empresa que base su actividad en un equipamiento que haya de transmitirse o que se haya transmitido para continuar con la misma, como es el servicio de apoyo como monitoras de comedor de un centro de enseñanza, pues se trata de una actividad típica en la que es la mano de obra el elemento más significativo. En este sentido la sentencia recurrida parte del hecho probado de que no fue objeto de transmisión ninguno de esos elementos de producción a que se refiere el artículo 1 de la Directiva, o el número 2 del artículo $44 \mathrm{ET}$, pues en modo alguno la transmisión afectaba a "una entidad económica que mantenga su identidad, entendida como un conjunto de medios organizados a fin de llevar a cabo una actividad económica, esencial o accesoria", como tampoco se produjo la referida figura de la sucesión de plantilla, puesto que el Liceo procedió a asumir la actividad en el control del comedor únicamente con su propio personal y algunas personas voluntarias».

También el conjunto de Sentencias que resolvieron la reversión del Ministerio de Defensa del servicio de cocina y restauración de diversas instalaciones militares, señalaron, reiterando la doctrina jurisprudencial del TJUE, que «la identidad de una entidad económica como la controvertida en el asunto principal, que descansa esencialmente en la mano de obra, no puede mantenerse si el supuesto cesionario no se hace cargo de la mayor parte de su plantilla» (STS de 19 de septiembre de 2017, RJI2017\4447; RJI2017\4527; RJI2017\4481; RJ(2017\4477). En todo caso, debe advertirse que en este caso no se resolvía un supuesto de sucesión de plantillas, sino una subrogación legal ordinaria, tal como hemos señalado supra.

1 En este sentido la ya mencionada STS de 21 de abril de 2015, RJI2015/2177: «Asimismo sostenemos con reiteración que cuando la empresa que venía llevando a cabo la actividad del servicio de mantenimiento mediante sucesivas contratas con diferentes empresas, decide asumir aquélla y realizarla por sí misma, sin hacerse cargo del personal de la empresa contratista, no puede decirse que se haya producido una sucesión de empresa encuadrable jurídicamente en el art. 44ET y en la Directiva 2001/23, de tal forma que los trabajadores que dejen de prestar su actividad por tal hecho han de considerarse despedidos por la empresa contratista y no cabe atribuir responsabilidad alguna a la principal (SSTS 6/02/97;... 27/06/08; 30/05/11; 11/07/11; SG 23/09/14, FJ 8.C; SG 17/11/14 (...)». 


\section{REVERSIÓN Y SUBROGACIÓN CONVENCIONAL O CONTRACTUAL}

El principal mecanismo a través del cual se consigue la subrogación de los trabajadores es la subrogación convencional; es decir, aquella que se produce, no por mandato de la ley, sino como consecuencia de que así se haya pactado en el convenio colectivo de sector aplicable a ambas contratistas. Estaríamos ante supuestos en los que la sucesión de contratas no se considera sucesión de empresas (si estuviésemos ante supuestos de sucesión empresarial operaría directamente el art. 44 ET y se trataría de una subrogación legal), de manera que el convenio amplía la protección subrogatoria a estos supuestos de sucesión de contratas. La cuestión que nos planteamos ahora es la aplicación de la subrogación convencional o a través del convenio a los supuestos de reversión de un servicio; es decir, si es aplicable la subrogación regulada en un convenio colectivo, cuando en vez de producirse una sucesión de contratas, se produce una reversión del servicio a la Administración titular del mismo.

A este interrogante ha dado solución la doctrina jurisprudencial, rechazando la posibilidad de imposición de la subrogación a la Administración a través del convenio colectivo. Así la STS de 17 de junio de 2011, RJI2011 5423 , que resolvía el caso del Ayuntamiento de Yunquera de Henares, que asumió el servicio de limpieza viaria que antes prestaba una contratista privada (sobre la misma actividad y con idéntica respuesta, vid. las SSTS de 11 de julio de 2011, RJI2011 15667; y 26 de julio de 2012, RJ 1201219976), señalando la inexistencia de subrogación por imposición del convenio colectivo, dando para ello varios argumentos:

«a) La sentencia de esta Sala de 10/12/08 (rcud. 2731/07), con cita de la de 28/10/96 (rcud. $566 / 96)$, señaló que "el convenio colectivo no puede (...) en su contenido normativo, establecer condiciones de trabajo que hubieran de asumir empresas que no estuvieran incluidas en su ámbito de aplicación. Así lo deja precisado el invocado art. 82.3 del citado Estatuto de los Trabajadores al disponer que los convenios colectivos regulados por su Título III obligan a todos los empresarios y trabajadores incluidos en su ámbito de aplicación en el que solo pueden estar comprendidos quienes, formal o institucionalmente, estuvieron representados por las partes intervinientes en la negociación del convenio" pues "la empresa que asume la limpieza de sus propios centros de trabajo (....) no desnaturaliza ni amplía el ámbito funcional de la empresa que asume tal actividad (...) y de ahí que el mero hecho de que una empresa decida realizar la limpieza de sus propios locales o centros de trabajo directamente y con su propio personal, aunque éste sea de nueva contratación, no la convierte en modo alguno en una empresa dedicada a la actividad de limpieza de edificios y locales ajenos".

b) De acuerdo con el criterio que se acaba de expresar, aunque la limpieza viaria sea una competencia municipal conforme a los arts. 25 y 26 de la Ley $7 / 85$, de 2 de abril, de Bases de Régimen Local, tampoco el hecho de que el Ayuntamiento asuma esta limpieza viaria con sus propios medios convierte a la entidad local en una empresa dedicada a la actividad de limpieza pública, viaria etc., como ocurre con la empresa contratista Urbaser, S. A. que cesó en la contrata de ejecución del servicio que le había adjudicado el Ayuntamiento, entre otras razones porque tal asunción del servicio podría realizarse con personal no laboral (art. 6 del repetido Convenio General del Sector).

c) En todo caso, lo que no puede estimarse aplicable en el caso que nos ocupa es la subrogación del personal que regula el art. 49 del Convenio General del Sector de Limpieza Pública Viaria etc., a efectos de contribuir y garantizar el principio de estabilidad en el empleo, porque, acorde con el criterio que expusimos anteriormente, la absorción del personal se prevé solamente "entre quienes se sucedan, mediante cualquiera de las modalidades de contratación de gestión de servicios públicos, contratos de arrendamiento de servicios o, de otro tipo, en una concreta actividad de las reguladas en el ámbito funcional del presente convenio", precisando en el art. 52 que la subrogación de personal "operará en todos los supuestos de sustitución de contratas...", siendo evidente que el Ayuntamiento que tenía adjudicado el servicio de limpieza viaria a una empresa del sector, cuando rescinde dicha adjudicación y asume directamente la ejecución del servicio público, no actúa como otro contratista del sector que obtenga una nueva adjudicación ni que suceda en la contrata a otro contratista anterior».

En el mismo sentido la STS de 21 de abril de 2015, RJI2015\2177, ya comentada y que resolvía el supuesto de la reversión de la cafetería de la Intervención General del Estado (y con idéntica literalidad la STS de 19 de mayo de 2015, RJI2015\2886, también comentada y relativa a la recuperación del servicio de 
GAPP. Nueva Época - N. 21, Mayo-Octubre 2019 - ISSN: 1989-8991 - DOI: 10.24965/gapp.v0i21.10553 - [Págs. 41-60]

restauración del Palacio de Congresos de Madrid), y que ante el planteamiento de una posible subrogación convencional, señalaba que

«Aunque está claro que la regulación convencional mejora -y mucho- las prescripciones estatutarias, de todas formas no cabe olvidar, como regla general y sin perjuicio de excepcionales irrupciones en el ámbito sectorial por parte de empresas en principio ajenas a él [supuestos -por ejemplo- como el de las SSTS 21/10/10 -rcud. 806/10 - (...) 23/09/14 -rco. 50/13-], que el convenio colectivo no puede contener cláusulas obligacionales que afecten a quienes no son parte en la negociación, ni en su contenido normativo cabe establecer condiciones de trabajo que hubieran de asumir empresas que no estuvieran incluidas en su ámbito de aplicación. Así se infiere del art. 82.3ET, al disponer que los convenios colectivos regulados por su Título III obligan a todos los empresarios y trabajadores incluidos en su ámbito de aplicación, en el que sólo pueden estar comprendidos quienes, formal o institucionalmente, estuvieron representados por las partes intervinientes en la negociación del convenio (entre las recientes, SSTS 21/12/10 -rco 208/09-; 11/07/11 -rcud 2861/10-; 17/09/12 -rcud 2693/11-; 18/09/12 -rcud 3299/11-; y 19/09/12 -rcud 3056/11-). Y en caso de autos, entre los pactantes de la normativa de cuya aplicación se trata fueron diversas asociaciones empresariales de hostelería y varias organizaciones sindicales, estando ausente representación alguna de las Administraciones Públicas, que obviamente no pueden quedar vinculadas por los pactos y acuerdos a que aquellas partes hubiesen llegado (...)».

En definitiva, dos son los argumentos utilizados por la jurisprudencial para negar que sea posible la subrogación: el convenio no puede afectar a quien no está incluido en el ámbito funcional del mismo (en este caso la Administración); y los convenios regulan situaciones de sucesión de contratas, fenómeno en el que no encaja la reversión que es un supuesto diferente.

La doctrina laboral, por su parte, ha seguido, en líneas generales la misma dirección fijada por la jurisprudencia, estimando mayoritariamente que no es posible aplicar la subrogación convencional a las Administraciones, al entender que los convenios no pueden afectar a empresas, como la Administración, que están fuera del ámbito funcional del convenio, pudiendo este afectar tan sólo a aquellas empresas incluidas dentro del ámbito de aplicación del mismo. Ciertamente la reversión pondrá final a una serie de contratas sucesivas, en las que puede haberse producido la subrogación por parte de las empresas entrantes; pero esta subrogación no es posible si la Administración recupera el servicio, al no estar incluida en el ámbito de aplicación del convenio; estaríamos ante un sujeto ajeno al convenio que regula la subrogación (Cruz, 2016, 42; Gómez, 2004, 282; Navarro, 2016, 316 y ss.; López, 2017, 126 y ss.; Sala, 2018, 204). Si embargo, también hay planteamientos críticos y favorables a la aplicación del convenio (así, Rodríguez, 2017, 27, Madrigal y Martínez, 2015, 40). De otro lado, también ha de considerarse que los convenios colectivos que establecen la subrogación convencional están regulando supuestos de sucesión de contratistas; es decir, que una empresa contratista que ve finalizar su contrato con la Administración es sustituida por una empresa saliente que contrata el mismo servicio con la Administración. Esta situación no es, ni mucho menos idéntica al supuesto de la reversión del servicio en la propia Administración, por lo que difícilmente podría aplicarse la subrogación a la Administración (en sentido crítico, Navarro, 2016, 328).

No obstante lo anterior, una reciente sentencia ha planteado una solución diferente, si bien la situación es distinta a la planteada habitualmente. Me refiero a la STS de 27 de febrero de 2018, RJI2018/1144: en este caso nos encontramos con una empresa mercantil, Giahsa, creada por la Mancomunidad de Servicios de Huelva, integrada a su vez por diferentes Municipios de la provincia onubense; es decir, tenemos una empresa mercantil creada indirectamente por los Ayuntamientos a través de la Mancomunidad y que gestiona los servicios de agua y recogida de residuos sólidos. Dicha empresa cuenta con su propio convenio colectivo, que para el caso de no mantenerse la entidad en la configuración inicial, prevé que se adoptarán los acuerdos necesarios para transferir el personal necesario al Ayuntamiento que abandone la entidad. Además, el convenio estatal del sector de limpieza pública y viaria, riesgos, recogida, tratamiento y eliminación de residuos, limpieza y conservación de alcantarillado, establece que en caso de sucesión de contratas, incluyendo la reversión o rescate de la contrata, los trabajadores de la empresa saliente pasarán a adscribirse a la nueva empresa o a la entidad pública que realice el servicio.

En el caso en cuestión, el Ayuntamiento de San Juan del Puerto acordó separarse de la Mancomunidad y recuperar la gestión de los servicios de recogida de servicios sólidos, adjudicando los mismos a una empresa contratista. Giahsa entregó al Ayuntamiento la documentación exigida en caso de sucesión de contra- 
tos y comunicó a la nueva contratista del Ayuntamiento de San Juan del Puerto la subrogación, contratista que se negó a la misma.

La sentencia parte de la inaplicación al Ayuntamiento del convenio nacional del sector, por idénticos argumentos a los señalados supra: no hay subrogación legal, pues no hay entrega de un soporte material para el desarrollo de la actividad, y tampoco puede aceptarse la subrogación convencional pues el convenio colectivo nacional no puede establecer reglas obligacionales que afecten a quien no es parte de la negociación, ni puede resultar de aplicación el convenio a quien no está incluido en el ámbito de aplicación del mismo. No obstante, estima la sentencia que no resulta de aplicación dicha doctrina al presente caso:

«Ahora bien, esa general inaplicabilidad del Convenio Colectivo a terceros no sería predicable de una cláusula -la de asunción de los trabajadores por los respectivos Ayuntamientos en supuesto de inviabilidad de la empresa pública y de asunción de la gestión- respecto de la que tales Administraciones Locales no pueden en puridad calificarse de "terceros", en tanto que "Giahsa" es una empresa pública instrumental creada para el cumplimiento de servicios públicos locales y precisamente por la Mancomunidad de la que el Ayuntamiento demandado forma parte; y menos aún respecto de la asunción directa del servicio, porque ello ya no sería consecuencia de la previsión convencional, sino más rectamente de la norma laboral y de la jurisprudencia (...) de lo que aquí se trata no es de extenderle la titularidad empresarial por el sólo hecho de titular del servicio público o creador de la entidad empresarial, sino tan sólo de imputar a los Ayuntamientos, creadores indirectos -a través de la Mancomunidad- de la sociedad pública instrumental, de una previsión convencional que directamente les afecta y que en manera alguna puede considerarse "ajena" e inaplicable a ellos, habida cuenta del régimen jurídico tutelar que respecto de tales sociedades les corresponde [vid. art. 47 Ley 5/2010, de 11/Junio]».

No obstante, finalmente no llegó a estimarse la subrogación en el Ayuntamiento, sino en la empresa contratista que asumió la gestión del servicio. Ahora bien, es evidente que de no haberse externalizado nuevamente el servicio a través de dicha tercera empresa, sería el Ayuntamiento quien, en base al propio convenio colectivo de Giahsa, debería haber asumido al trabajador demandante. Como vemos, si es posible la subrogación convencional, cuando es el convenio que afecta a la Administración el que prevé la subrogación de personal procedente de contratistas.

En este sentido, debemos recordar lo señalado en el art. 130.3 de la Ley 9/2017: «En caso de que una Administración Pública decida prestar directamente un servicio que hasta la fecha venía siendo prestado por un operador económico, vendrá obligada a la subrogación del personal que lo prestaba si así lo establece una norma legal, un convenio colectivo o un acuerdo de negociación colectiva de eficacia general».

Aparentemente este precepto admite la subrogación convencional, pues establece que la Administración está obligada a la subrogación si lo establece una norma legal (subrogación legal) o un convenio colectivo o acuerdo de eficacia general. No obstante, dicha literalidad, a mi juicio, no da carta de naturaleza a la subrogación convencional, cuando esta se regula en un convenio colectivo cuyo ámbito funcional de aplicación no incluye a la Administración, al no ser esta sujeto negociador del mismo. Se estaría refiriendo realmente al supuesto de convenios en los que la propia Administración esté representada en la mesa negociadora; de lo contrario se estaría admitiendo que sujetos ajenos a la Administración pueden negociar obligaciones que se impongan a la misma.

Para terminar con las posibilidades de subrogación, debemos recordar al supuesto de la subrogación establecida por los pliegos de condiciones. En este caso se trata de una subrogación impuesta por la Administración a los licitadores a contratos de gestión de servicios públicos o en la regulación actualmente vigente a contratos de concesión de servicios; por lo tanto, no tiene lógica que esta posibilidad de subrogación pueda afectar a las Administraciones, pues son ellas las que concretan las condiciones de los pliegos que afectan a los sujetos privados. Estaríamos ante un supuesto de autoimposición de la subrogación por parte de la propia Administración, lo cual tiene una escasa lógica (Cruz, 2016, 42 y 43; Monereo, 2016, 292; Navarro, 2016, 316; Sala, 2018, 204).

El pliego de condiciones juega en realidad un mero papel informador para los licitadores que desean acceder a la contratación con la Administración; así con anterioridad señalamos que el art. 130 de la Ley 9/2017, establece en su apartado primero que en aquellos casos de sucesión de contratistas con la Administración, si existe la posibilidad de una subrogación legal o convencional, el pliego de condiciones juega dicho papel informador, pues los órganos de contratación «(...) deberán facilitar a los licitadores, en el propio pliego, la información sobre las condiciones de los contratos de los trabajadores a los que afecte la subro- 
gación que resulte necesaria para permitir una exacta evaluación de los costes laborales que implicará tal medida, debiendo hacer constar igualmente que tal información se facilita en cumplimiento de lo previsto en el presente artículo». Dicha información debe ser facilitada por la propia empresa saliente al órgano de contratación, de manera que «El pliego de cláusulas administrativas particulares contemplará necesariamente la imposición de penalidades al contratista dentro de los límites establecidos en el artículo 192 para el supuesto de incumplimiento por el mismo de la obligación prevista en este artículo» (art. 130.4 Ley 9/2017).

Además, el apartado $6 .^{\circ}$ de este art. 130 establece un refuerzo para las garantías de los trabajadores, pues prevé que «Asimismo, y sin perjuicio de la aplicación, en su caso, de lo establecido en el artículo 44 del texto refundido de la Ley del Estatuto de los Trabajadores, aprobado por Real Decreto Legislativo 2/2015, de 23 de octubre, el pliego de cláusulas administrativas particulares siempre contemplará la obligación del contratista de responder de los salarios impagados a los trabajadores afectados por subrogación, así como de las cotizaciones a la Seguridad social devengadas, aún en el supuesto de que se resuelva el contrato y aquellos sean subrogados por el nuevo contratista, sin que en ningún caso dicha obligación corresponda a este último. En este caso, la Administración, una vez acreditada la falta de pago de los citados salarios, procederá a la retención de las cantidades debidas al contratista para garantizar el pago de los citados salarios, y a la no devolución de la garantía definitiva en tanto no se acredite el abono de éstos». Con ello se ofrece a los trabajadores un mecanismo que incrementa su protección, especialmente en el supuesto de subrogaciones convencionales, donde ya hemos visto la posibilidad de que se limiten los efectos de la subrogación, respecto del régimen legal, por la vía de establecer la falta de responsabilidad del nuevo empresario en materia de salario de los trabajadores subrogados (no así en el caso de subrogación legal, pues la garantía salarial se establece como efecto de la subrogación ex art. $44 \mathrm{ET}$; salvo que interpretemos que este precepto garantiza los salarios más allá del plazo de prescripción de las acciones derivadas del contrato de trabajo).

\section{SUBROGACIÓN Y PRINCIPIOS DE IGUALDAD, MÉRITO Y CAPACIDAD}

Tal como viene destacando la doctrina laboral desde hace tiempo (Gómez, 2004, 282), la principal dificultad jurídica que plantea la existencia de una sucesión de empresas en el marco de una reversión de servicios administrativos es la articulación de las normas y principios laborales con las normas y principios administrativos: la subrogación y la estabilidad en el empleo del art. 44 ET con la regulación sobre procedimientos de selección del personal que obedecen a los principios constitucionales de igualdad, mérito y capacidad (vid. los arts. 23.2 y 103.3 de la Constitución, así como el art. 55 EBEP).

Es evidente que la asunción por parte de la Administración de trabajadores procedentes de una empresa privada, de manera directa, supone eludir los señalados principios constitucionales que implican la necesidad de superar unas de pruebas de selección, a las que podrían acceder todos los ciudadanos que cumpliesen los requisitos que se establezcan para cada proceso de selección.

La doctrina apuntó como solución la consolidación de este personal como indefinido no fijo (Gómez, 2004, 287 y 288; Sala, 2018, 205 y 206), estableciendo así un paralelismo con aquellos supuestos en los que la contratación temporal fraudulenta por parte de la Administración generaba la incorporación de personal, inicialmente contratado a través de un contrato meramente temporal, como indefinido en aplicación del art. 15.3 ET. Estaríamos ante una nueva vía de generación de trabajadores indefinidos no fijos.

Tal como acabamos de señalar, esta categoría o calificación propia del personal laboral al servicio de Administraciones Públicas, surge como consecuencia del incumplimiento por parte de la Administración del régimen jurídico de los contratos temporales. Por el contrario, cuando nos planteamos un supuesto de subrogación por reversión de un servicio, estos trabajadores acceden a la Administración sin que ésta cometa violación alguna del ordenamiento, al contrario, se incorporan justamente en cumplimiento de las normas sobre subrogación. El punto de unión entre ambas tipologías generadoras de trabajadores indefinidos no fijos reside en el acceso a la función pública sin procedimiento de selección, y que mantendrían u vinculación definitiva con la Administración en función de que logren acceder de manera ordinaria a la misma tras un procedimiento de selección, pudiendo suprimirse el puesto de trabajo que ocupan, quedando abocados a la extinción del contrato.

Esta solución tiene difícil encaje con lo previsto por la Directiva 2001/33 y con el art. 44 ET (Monereo, 2016, 304 y ss.), pues esta regulación se basa en garantizar la estabilidad en el empleo de los trabajadores afectados por lo dispuesto por el art. $44 \mathrm{ET}$; y el indefinido no fijo supone hacer pender el mantenimiento del empleo a la consecución de un puesto de trabajo previo proceso de selección. De otro lado, es 
evidente que la regulación laboral que acabamos de mencionar no prevé la mutación que supone el indefinido no fijo para la relación laboral. Parece una solución de compromiso entre los dos planteamientos: la necesidad de dar cumplimiento a lo dispuesto por el art. 44 ET y la necesidad de respetar los principios constitucionales de igualdad, mérito y capacidad. Es evidente que una respuesta que anulase uno de los dos extremos generaría una situación del todo rechazable, pues ni es factible eliminar los efectos subrogatorios contemplados por el art. 44 ET y por la Directiva comunitaria, ni es posible defraudar principios constitucionales básicos.

Consecuentemente, la Administración, al incorporar este personal debería proceder tarde o temprano a la creación de las plazas para este personal, implementando el proceso de selección (al que podrá optar libremente el trabajador, junto con el resto de posibles candidatos, caso de ser él quien obtuviese la plaza, pasaría a tener condición de fijo; caso de ser otro sujeto diferente, se extinguiría el contrato de trabajo -sin indemnización- por haberse ocupado la plaza a través del oportuno proceso de selección); o bien, si no existen verdaderas y reales necesidades de servicio, proceder a la amortización de los contratos a través del despido objetivo o en su caso colectivo (Rodríguez, 2017, 31), siendo de aplicación en estos casos las especialidades propias del despido reguladas en el EBEP, en la DA 16. ${ }^{a}$ del ET y en el RD 1483/2012 por tratarse de personal perteneciente a una Administración Pública (Rodríguez, 2017, 34).

La solución, a mi juicio, no es satisfactoria, pues a diferencia del indefinido no fijo, que es un trabajador que, al menos según la interpretación canónica, está abocado a ver extinguido su contrato salvo que supere un proceso de selección para adquirir la condición de fijo, una vez que la plaza que ocupa salga a concurso; el trabajador subrogado no debería tener este horizonte, pues se incorpora a la Administración como consecuencia de la aplicación de un mandato legal y sin que exista una situación de fraude en la contratación.

No obstante, si la reversión se realizase a una sociedad mercantil o una persona jurídico privada en mano pública, al no tener la consideración de ente público (forman parte del sector público, pero carecen de personalidad jurídico-pública), serían aplicables las reglas propias del ET, sin especialidad alguna. No se accedería en condición de indefinido no fijo, figura que es aplicable sólo a los empleados públicos, sino en la condición de trabajador indefinido ordinario, y se le aplicaría exclusivamente la regulación laboral ordinaria.

De otro lado, ha de advertirse que en la actualidad ya no es posible atribuir al personal de la Administración pública la condición de indefinido no fijo de manera directa, sino que es imprescindible que dicha consideración derive de una sentencia judicial. Así lo afirma el apartado Dos de la DA 34. ${ }^{a}$ de la Ley 3/2017, de 27 de junio, de PGE para el año 2017: «(...) los órganos de personal citados no podrán atribuir la condición de indefinido no fijo a personal con un contrato de trabajo temporal, ni a personal de empresas que a su vez tengan un contrato administrativo con la Administración respectiva, salvo cuando ello se derive de una resolución judicial»; regla que se reitera por la DA 43. ${ }^{a}$ de la Ley $6 / 2018$, de 3 de julio, de PGE para el año 2018. Por lo tanto, no cabe la posibilidad de reconocer la condición de indefinidos no fijos, si no es a través de una sentencia que así lo haga expresamente. Esta regulación veda o impide, a mi juicio, la posibilidad de utilizar la figura del indefinido no fijo en caso de subrogación por reversión del servicio.

Por otra parte, respecto de los trabajadores sometidos a contratación temporal de obra y servicio por parte de la empresa contratista (fenómeno bastante habitual), debe tenerse en cuenta que si el contrato condiciona el fin del contrato a la finalización de la obra o servicio, y este se identifica con la extinción de la contrata, los contratos se extinguirían sin que este personal pasara a incorporarse a la Administración.

En definitiva, la solución propuesta no es aceptable. Es por ello que hay autores que reclaman la intervención del legislador para resolver esta cuestión (Sala, 2018, 206). Justamente es lo que ha intentado hacer el legislador a través de la LPGE de 2017, introduciendo una DA 26. ${ }^{a}$ que se enfrenta a este problema jurídico, cuestión diferente es que la literalidad de la norma genere dudas tremendamente relevantes.

\section{LIMITACIONES A LA REVERSIÓN: LA DISPOSICIÓN ADICIONAL 26. a DE LA LPGE PARA 2017}

Tal como hemos señalado, en la situación actual se está procediendo a un proceso contrario a la externalización, siendo una importante novedad, especialmente en el ámbito de las Administraciones locales. Las consecuencias que este proceso puede conllevar ha hecho que el legislador tome nota de cómo el péndulo parece volver a su punto de partida y, ante el temor a las consecuencias que puede traer la subrogación de los trabajadores, se ha optado por establecer ciertas limitaciones a los efectos de las reversiones. Me refiero, 
como no, a lo previsto por la Disp. Adic. 26. a de la Ley 3/2017, de 27 de junio, de Presupuestos Generales del Estado para $2017^{2}$.

La primera cuestión que debemos resaltar de este precepto es que no estamos ante una norma de duración limitada a los efectos de la LPGE de 2017, sino que su vigencia tiene carácter indefinido, tal como el propio precepto se encarga de aclarar. Por lo tanto, las normas que pretenden limitar los efectos de la reversión, no agotan su vigencia con los presupuestos del 2017, teniendo pretensión de ser aplicadas hasta que el legislador acuerde su derogación. Más aún, ha de tenerse en cuenta que el apartado tercero de este precepto señala que lo regulado en esta disposición adicional tiene carácter básico, por lo que resulta de aplicación a todas las Administraciones públicas.

A tenor de la literalidad del precepto mencionado, las Administraciones públicas que están incluidas en el art. 2 del EBEP (la AGE, las CCAA, las Entidades locales, los organismos públicos, agencias y otras entidades de derecho público con personalidad jurídica propia, que están vinculadas o dependen de las AAPP y las Universidades), no podrán otorgar la consideración de empleados públicos regulada en el art. 8 del EBEP ni podrán incorporar con dicha condición a los trabajadores que desarrollaban prestación de trabajo para los contratistas de obra o servicios o que mantenían cualquier contrato adjudicado por una Administración de las mencionadas en el art. 2 de la Ley 40/2015 (las mismas del art. 2 del EBEP), cuando los contratos se extingan ya sea por cumplimiento, resolución del contrato, incluido el rescate. Es decir, que los trabajadores de esas empresas contratistas, cuando se produzca la reversión, no podrán incorporarse a las Administraciones como empleados públicos. Téngase en cuenta que tampoco podrán incorporarse con esta condición el personal laboral que presta servicios en sociedades mercantiles públicas, fundaciones o consorcios que se integran en una Administración Pública, pese a que tales entidades forman parte del sector público (art. 3 de la Ley 9/2017), y pese a que este personal haya debido pasar procesos de selección para su contratación.

Esta norma supone un límite a la incorporación de personal laboral, no en vano el propio precepto se titula como «Limitaciones a la incorporación de personal laboral al sector público» (Treviño, 2017, 163; Trillo, 2017 , 9). Además, su ámbito de aplicación es muy amplio, pues el apartado primero del precepto se remite al art. 2 del EBEP que contempla tanto a Administraciones territoriales como a organismos públicos, agencias o demás entidades de derecho público con autonomía jurídica propia, dependientes de las Administraciones Públicas. Por lo tanto las reversiones y los trabajadores afectados son tanto aquellas en las que se opta por una gestión directa integrada en la propia Administración, como aquellas en las que la gestión vaya a realizarla una entidad personificada; de hecho el propio precepto señala que ni se pueden considerar empleados públicos, ni se podrán incorporar con esta condición en una Administración Pública o en una entidad de derecho público, englobando, de esta manera, un amplio conjunto de destinos de este personal laboral.

Al respecto, parece conveniente una aclaración relativa a las empresas públicas o sociedades mercantiles, que forman parte del sector público, pero no tienen personalidad jurídico-pública, por lo que no tienen la consideración de entidades públicas. Dicho de otro modo, escapan al ámbito de aplicación de la DA 26.a; es decir, expresándolo en sentido positivo, sí podrían incorporar a estos trabajadores a sus plantillas sin los límites de dicha disposición (López, 2017, 131).

Es evidente que la pretensión del legislador con esta norma es limitar los efectos de la subrogación en caso de reversión, de manera que, en estos casos, si la Administración está afectada por el art. 44 ET, no

${ }^{2}$ La actual redacción del precepto (modificado por la Ley 6/2018, de 3 de julio, de Presupuestos Generales del Estado para 2018) es la siguiente: «Disposición adicional vigésima sexta. Limitaciones a la incorporación de personal laboral al sector público.

Uno. Con efectos desde la entrada en vigor de esta Ley y vigencia indefinida, las Administraciones Públicas del artículo 2 del texto refundido de la Ley del Estatuto Básico del Empleado Público, aprobado por el Real Decreto Legislativo 5/2015, de 30 de octubre, no podrán considerar como empleados públicos de su artículo 8, ni podrán incorporar en dicha condición en una Administración Pública o en una entidad de derecho público:

a) A los trabajadores de los contratistas de concesiones de obras o de servicios públicos o de cualquier otro contrato adjudicado por las Administraciones Públicas previstas en el artículo 2.3 de la Ley 40/2015, de 1 de octubre, de Régimen Jurídico del Sector Público, cuando los contratos se extingan por su cumplimiento, por resolución, incluido el rescate, o si se adopta el secuestro o intervención del servicio conforme a la legislación de contratos del sector público que resultase aplicable a los mismos.

b) Al personal laboral que preste servicios en sociedades mercantiles públicas, fundaciones del sector público, consorcios, en personas jurídicas societarias o fundacionales que vayan a integrarse en una Administración Pública.

Dos. En aquellos supuestos en los que, excepcionalmente, en cumplimiento de una sentencia judicial, o previa tramitación de un procedimiento que garantice los principios constitucionales de igualdad, mérito y capacidad, el personal referido en el apartado 1.a) anterior sea incorporado a sociedades mercantiles públicas, las incorporaciones que se produzcan de acuerdo con lo previsto en este apartado, no se contabilizarán como personal de nuevo ingreso del cómputo de la tasa de reposición de efectivos.

Tres. Lo establecido en esta disposición adicional tiene carácter básico y se dicta al amparo de lo dispuesto en los artículos 149.1. 13. ${ }^{a}$ y 18. ${ }^{a}$, así como del artículo 156.1 de la Constitución». 
podrán incorporar al personal procedente de una reversión como empleados públicos, dificultando el futuro de los trabajadores de empresas privadas afectadas por procesos de reversión de servicios públicos (López, 2017 , 105). A ello anima también la modificación de la DA 26. ${ }^{a}$ realizada por la LPGE de 2018, pues se ha eliminado el último párrafo del apartado uno, que establecía que «Al personal referido en los apartados anteriores le serán de aplicación las previsiones sobre sucesión de empresas contenidas en la normativa laboral».

Teniendo en cuenta ambos elementos, llegamos a una situación cuanto menos confusa, por no decir directamente que contradictoria: en los casos de reversión, si se cumplen los requisitos, será de aplicación la normativa laboral sobre subrogación; pero ese personal no podrá incorporarse a las Administraciones como empleados públicos. Es evidente que la conjunción entre normas laborales y administrativas se apetece especialmente confusa y compleja,

¿Cómo es posible resolver esta situación aparentemente tan contradictoria? A mi juicio la norma, si bien pretende limitar los efectos de los procesos de reversión, sobre todo remunicipalización, que se están produciendo en la actualidad (Treviño, 2017, 162), no lo hace impidiendo la subrogación de las Administraciones públicas, sino reduciendo los efectos del proceso por la vía de negar la consideración de empleados públicos a los trabajadores afectados.

La DA 26. a no puede impedir la aplicación de la subrogación en los casos de reversión, pues estaría actuando en contra de la Directiva 2001/23, que tal como hemos visto resulta aplicable a las Administraciones. Entra dentro de la competencia del legislador nacional reforma las leyes como el ET, de manera que no se aplique o lo haga de manera limitada. Ello es posible, ahora bien, no cabe la menor duda de que el legislador no puede actuar contra la letra de la Directiva, ni contra la interpretación que de la misma realiza el TJUE. Por lo tanto, como punto de partida, y esto es esencial, esta regulación no puede, en modo alguno, suponer una reducción de los efectos del art. 44 ET, de manera que si se cumplen las exigencias legales, habrá subrogación empresarial por parte de la Administración.

Más aún, la subrogación se establece como obligatoria en la propia regulación de contratos públicos, pues el art. 130.3 Ley 9/2017 (norma posterior a la LPGE de 2017), con absoluta claridad establece que «En caso de que una Administración Pública decida prestar directamente un servicio que hasta la fecha venía siendo prestado por un operador económico, vendrá obligada a la subrogación del personal que lo prestaba si así lo establece una norma legal, un convenio colectivo o un acuerdo de negociación colectiva de eficacia general». Obsérvese que este precepto admite incluso la subrogación convencional. Ahora bien, debemos entender que ello es así, siempre y cuando el convenio sea negociado también por la Administración, de manera que esta entre dentro del ámbito de aplicación del mismo.

Por otra parte, la supresión del último párrafo del apartado Uno de la DA 26. a , tampoco supone negar la aplicación del art. 44 ET. La supresión puede explicarse por el hecho de que el apartado Uno de la DA 26. ${ }^{a}$, que predicaba expresamente la aplicación de normas sobre sucesión de empresas contenidas en la regulación laboral, se refiere a dos colectivos diferentes: de un lado, el personal procedente de sucesión de contratas, y de otro el personal que presta servicios en personas jurídico-privadas, pero que forman parte del sector público, que se integran en la Administración pública como supuesto de transformación de entes del sector público. Pues bien, respecto del segundo de los colectivos, la subrogación se plantea normalmente a través de normas legales específicas dedicadas a regular la reestructuración del sector público (normas, por tanto, de Derecho Administrativo); de ahí que se obvie la referencia a la sucesión de empresas regulada «en la normativa laboral».

Por lo tanto, la DA 26. a admite la subrogación del personal, su incorporación; ahora bien no con la condición de empleados públicos. Es aquí donde está realmente la clave de esta regulación. Recordemos que a tenor del art. 8 EBEP son empleados públicos, los que desempeñan funciones retribuidas en las Administraciones y, clasificándose en funcionarios de carrera, interinos, personal eventual y (por lo que a nosotros interesa ahora) personal laboral, que podrá ser fijo, indefinido o temporal. Por lo tanto, el personal laboral de las letras a) y b) de la DA 26. ${ }^{\text {a }}$, se incorporará a la Administración, pero no como empleado público; es decir, sin integrarse en ninguna de las categorías del art. 8 EBEP. Esto supone, por ejemplo, que si es personal que tenía un contrato indefinido con la empresa privada no puede incorporarse a la Administración como fijo, pues la consideración de fijo es propia del empleado público, siendo una de sus clasificaciones ex art. 8 EBEP. Ello supondrá, por ejemplo, no beneficiarse de las garantías en caso de despido improcedente o de despidos colectivos.

De otro lado, tampoco podrán incorporarse como indefinidos no fijos, pues a tenor de la literalidad de la DA 26. ${ }^{a}$ estos trabajadores no pueden incorporarse con la condición de empleados públicos y el indefinido no fijo es empleado público a tenor del art. 8 EBEP; por lo tanto, tampoco podría ser esta la respuesta (Ló- 
pez, 2017,145). Todo ello, además, de las limitaciones que tiene la figura del indefinido no fijo, pues tal como hemos señalado anteriormente sólo es factible acceder a esta condición a través de sentencia judicial según la normativa de las leyes de presupuestos generales del Estado para los años 2017 y 2018.

Entonces, ¿en qué condición acceden a la Administración estos trabajadores? Lo cierto es que la DA 26. ${ }^{a}$ crea un limbo jurídico: es personal laboral, es personal laboral incorporado a una Administración, pero no en la condición de empleado público. Aparentemente la consecuencia de la DA $26 .^{\mathrm{a}}$ es la creación de un nuevo tipo de trabajadores de la Administración, que no tienen la consideración de empleados públicos, los trabajadores subrogados (López, 2017, 147).

Desde mi punto de vista, lo que pretende la DA 26. ${ }^{a}$ es aplicar la subrogación, de manera que los trabajadores se incorporan a la Administración, pero sin que resulte de aplicación el EBEP, pues no son empleados públicos. Si bien el legislador no ofrece un verdadero concepto de empleado público (el que aparece en el art. 8 es tan genérico que realmente casi todos los que prestan servicios para una Administración entrarían en la descripción que realiza), al menos sí establece la lista exhaustiva de sujetos que gozan de esta condición, siendo rasgo común a todos ellos que se les aplica el EBEP. De esta manera el EBEP (me refiero, como es lógico a las normas que específicamente señala el propio EBEP como aplicables al personal laboral) queda reservado para los que son empleados públicos; siéndoles, además, también de aplicación, como es lógico, el ET, así como el resto de normas de derecho público aplicables al personal laboral; por ejemplo, la regulación sobre incremento retributivo regulado por la LPGE de cada año (y ello con independencia de lo previsto por el art. $44.4 \mathrm{ET}$, pues no podría hacerse valer esta norma en la defensa de una aplicación de la retribución pactada en el convenio colectivo de origen, pues aun cuando no estemos ante trabajadores públicos en el sentido del art. 8 EBEP, es evidente que prestarán servicios para una Administración, por lo que están afectados por estos límites retributivos), o la tasa de reposición existente en cada momento.

Por el contrario, al personal laboral de las letras a) y b) del apartado Uno de la DA 26. ${ }^{a}$ LPGE de 2017 le será de aplicación exclusivamente el ET, así como esas otras normas de derecho público dictadas para ser aplicadas a los trabajadores, como los límites al incremento retributivo o las tasas de reposición a las que hemos hecho referencia. Esto supone no aplicar las reglas de protección en caso de despidos disciplinario y, específicamente, al que tenga contrato indefinido no se le aplicará la readmisión obligatoria en caso de improcedencia; y para todo este personal laboral se le aplicarán las reglas sobre despido objetivo y colectivo del ET sin interferencias del EBEP. Ahora bien, en materia de despidos colectivos y objetivos, recordemos que es el propio ET quien establece ciertas especialidades que dificultan la extinción por causas económicas, técnicas, organizativas o productivas, afectando al personal integrado en los entes, organismos y entidades que forman parte del sector público (DA16. $\left.{ }^{a} \mathrm{ET}\right)$.

La doctrina laboral ha señalado la posibilidad de que la Administración pueda crear sociedades mercantiles públicas que tengan como fin gestionar el servicio revertido y acoger a los trabajadores de la letra

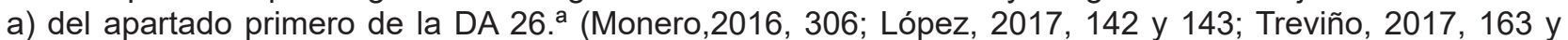
164), lógicamente bajo el régimen laboral común. Observemos que es una solución, ante todo, factible de conformidad a la propia DA 26. ${ }^{a}$, que en su apartado segundo señala que en los casos excepcionales, derivados del cumplimiento de una sentencia, o bien previa tramitación de un procedimiento que garantice los principios de igualdad, mérito y capacidad, el personal señalado por la letra a) del primer apartado de la DA 26. ${ }^{a}$ (trabajadores procedentes de contratistas de concesiones de servicios públicos), sea incorporado a sociedades mercantiles públicas, tales incorporaciones no se contabilizan como personal de nuevo ingreso a los efectos de la tasa de reposición. Dejando de lado la problemática de la tasa de reposición, es evidente que se está admitiendo la posibilidad de asunción del personal procedente de concesiones afectadas por reversión por parte de las sociedades mercantiles (más aún, la DA 15. ${ }^{a}$ de la Ley 3/2017, de 27 de junio, de Presupuestos Generales del Estado para 2017, establece que las limitaciones para la contratación de nuevo personal de las sociedades mercantiles públicas no serán de aplicación si el personal tuviese una relación preexistente, fija o indefinida con el sector público).

Estas sociedades mercantiles públicas se rigen en sus relaciones laborales por el Derecho del Trabajo, por lo que no surgirían los conflictos derivados de una incorporación como empleados públicos, pues su personal no tiene esta consideración, sino que se trata de personal laboral ordinario. No les resulta de aplicación el art. 8 EBEP ni las diferentes categorías de empleados públicos (López, 2017, 143). Sin embargo, recordemos que a estas sociedades si resulta de aplicación principios esenciales del derecho público, que afectan fundamentalmente al ámbito de la contratación: así, les afectan los límites cuantitativos en la contratación (la tasa de reposición), y deberán respetar los principios de igualdad, mérito y capacidad (DA 1. ${ }^{a}$ EBEP). 
En la práctica esta solución da satisfacción al objetivo perseguido por el legislador: evitar que la marea de reversiones suponga que el conjunto de empleados públicos crezca desmesuradamente, pues se establece un cortafuegos que es la sociedad mercantil pública, de manera que no alcance a las Administraciones o entidades públicas (incluso podría plantearse la creación de la sociedad con un fin meramente instrumental para volver a concertar la gestión con un tercer sujeto privado). De otro lado, se mantienen el derecho a la estabilidad de los trabajadores afectados que garantiza el art. $44 \mathrm{ET}$.

Como vemos, el cruce de normas laborales y administrativas crea importantes problemas interpretativos, lo que va a generar, a buen seguro, un importante nivel de polémica judicial a corto plazo, pues serán los jueces, en última instancia, quienes deban realizar una interpretación a este precepto.

\section{BIBLIOGRAFÍA}

CRUZ VILLALÓN, J. (2016): "Claves laborales de la participación privada en la actuación pública", en Temas Laborales, núm. 135, págs. 13-48.

GÓMEZ ALVAREZ, T. (2004): La transformación de las Administraciones Públicas. Madrid: CES.

GORELLI HERNÁNDEZ, J. (2007): La tutela de los trabajadores ante la descentralización productiva. Madrid: Grupo Difusión.

LÓPEZ CUMBRE, L. (2017): "Limitaciones a la incorporación de personal laboral en el sector público. Reglas de subrogación y empleo público", en Revista Galega de Dereito Social, núm. 3, págs. 101-147.

MADRIGAL ESTEBAN, M. J. y MARTÍNEZ SALDAÑA, D. (2015): "La subrogación de trabajadores y la sucesión de empresa en el ámbito de la contratación pública", en Actualidad Jurídica Uría Menéndez, núm. 40, págs. 33-51.

MONEREO PÉREZ, J. L. (2016): "Repercusiones laborales de los diversos instrumentos de privatización y reversión de servicios públicos", en Temas Laborales, núm. 135, págs. 251-308.

NAVARRO NIETO, F. (2016): "Gestión privada de lo público: estructura y contenido de la negociación colectiva", en Temas Laborales, núm. 135, págs. 309-344.

OLARTE ENCABO, S. (2016): "Calidad de los servicios públicos y estándares laborales. Especial referencia a la seguridad y salud laboral y a la conciliación familiar", en Temas Laborales, núm. 135, págs. 151-183.

DE LA PUEBLA PINILLA, A. (2016): "Problemas laborales en la «remunicipalización» de los servicios públicos", en Trabajo y Derecho, núm. 17, págs. 112-122.

RODRÍGUEZ ESCANCIANO, S. (2017): "Implicaciones jurídico-laborales de la reasunción de servicios públicos. La aplicación del principio de subrogación empresarial y sus excepciones", en Trabajo y Derecho, núm. 19, págs. 1939.

RODRÍGUEZ-PIÑERO ROYO, M. (2016): “Gestión privada, contratación temporal y calidad en el empleo", en Temas Laborales, núm. 135, págs. 111-150.

SALA FRANCO, T. (2018): "Acceso de los derechos de los trabajadores en los casos de reversión en la gestión de servicios públicos por las Administraciones públicas", en Derecho de las Relaciones Laborales, núm. 2, págs. 202206.

TREVIÑO PASCUAL, M. (2017): "Sucesión de plantillas y cesión de trabajadores en la gestión de servicios públicos", en Revista General de Derecho del Trabajo y de la Seguridad Social, núm. 47, págs. 126-166.

TRILLO PÁRRAGA, F. J. (2017): Externalización de servicios públicos y su impacto en los derechos laborales. Albacete: Bomarzo. 